\title{
CORRECTION
}

Check for updates

Cite this: RSC Adv., 2020, 10, 3715

DOI: 10.1039/d0ra90005b

rsc.li/rsc-advances

\section{Correction: The synthesis of calcium arsenateairon arsenate coating materials and their application for arsenic-containing wastewater treatment}

\author{
Yang Wang, ${ }^{a}$ Zhihao Rong, ${ }^{a}$ Xincun Tang ${ }^{\star a}$ and Shan Cao*b
}

Correction for 'The synthesis of calcium arsenate@iron arsenate coating materials and their application for arsenic-containing wastewater treatment' by Yang Wang et al., RSC Adv., 2020, 10, 719-723.

The authors regret that there were errors in the Characterization of samples section of the original article, in Section 3.1 on page 720 of the original article. These errors are detailed below.

The sentence beginning, "As is known, the main peaks of scorodite $\left(\mathrm{FeAsO}_{4} \cdot 2 \mathrm{H}_{2} \mathrm{O}\right)$ are located at approximately $30.1^{\circ}, 27.8^{\circ}$, $16.9^{\circ}$ and $10.9^{\circ} \ldots$ " should read, "As is known, the main peaks of $\mathrm{CaHAsO}_{4}$ are located at approximately $30.1^{\circ}, 27.8^{\circ}, 16.9^{\circ}$ and $10.9^{\circ}$, which can be indexed as the (221), (220), (101) and (020) lattice planes of $\mathrm{CaHAsO}_{4}$ (JCPDS no. 18-0288), respectively."

The sentence beginning, "As is known, the main peaks of scorodite located at approximately $30.8^{\circ}$ and $31.7^{\circ} \ldots$ " should read, "As is known, the main peaks of $\mathrm{Ca}_{3}\left(\mathrm{AsO}_{4}\right)_{2}$ located at approximately $30.8^{\circ}$ and $31.7^{\circ}$, can be indexed as the (020) and (021) lattice planes of $\mathrm{Ca}_{3}\left(\mathrm{AsO}_{4}\right)_{2}$ (JCPDS no. 01-0933)."

The Royal Society of Chemistry apologises for these errors and any consequent inconvenience to authors and readers. 